DOI 10.22478/ufpb.2317-6725.2019v24n41.47241

\title{
O feminino sacralizado e a violência de gênero no Cariri: do processo-crime à poesia
}

\author{
Polliana de Luna Nunes Barreto \\ https://orcid.org/0000-0003-3936-6002 \\ Universidade Regional do Cariri \\ Patrícia Helena Carvalho Holanda \\ D https://orcid.org/0000-0002-8233-1190 \\ Universidade Federal do Ceará
}

The sacred female and gender violence in Cariri: from crime process to poetry

\begin{abstract}
Resumo: Neste artigo, discutimos os elementos discursivos comuns sobre gênero constantes nos discursos da religião católica, do Direito, da escola e da Literatura que circularam na região do Cariri no século XX e, em alguma medida, relacionam-se com as narrativas em torno das mulheres santificadas popularmente na referida região. $O$ processo de santificação popular do feminino no Cariri se construiu historicamente e se relaciona com o discurso penitencial católico e com a violência de gênero ainda recorrente na contemporaneidade. Os resultados aqui apresentados são frutos de uma pesquisa histórica, sendo a análise alicerçada nas produções teóricas da História Cultural. As fontes são múltiplas e advêm da História Oral através da produção de entrevistas, de coleta documental contemplando as fontes judiciais, a Literatura de Cordel, documentos escolares e fotografias. A decisão por ampliar o bojo de fontes e analisá-las conjuntamente se deu diante da complexidade temática e do ímpeto de construir algumas compreensões em relação ao impacto da construção discursiva sobre o feminino na produção simbólica da santidade de mulheres naquele lócus. A Ciência, a escola, o Processo Penal, a Literatura e a Igreja Católica são instrumentos de divulgação de valores, pautam a circulação de ideais e representações sociais e foram importantes veículos para apropriação e representação do feminino. A despeito das várias produções normativas e científicas que tratam da autonomia dos gêneros e das mudanças sociais que viabilizam uma maior atuação do feminino na esfera pública nas últimas décadas, observamos que no Cariri cearense a representação do feminino ainda se propagada de modo relacionado aos ideais da família nuclear e o plano da cultura se instrumentaliza em torno dos valores e papeis de Gênero consolidados há dois séculos. Essa construção representativa contribui para a manutenção dos papeis e dá vazão à violência de gênero.
\end{abstract}

Palavras-chave: Gênero. Representações. Violência.

Abstract: In this article, we discuss the common discursive elements of gender contained in the discourses of Catholic religion, law, school, and literature that circulated in the Cariri region in the twentieth century and, to some extent, relate to narratives around women. popularly sanctified in that region. The process of popular sanctification of the female in Cariri has been historically built and is related to the Catholic penitential discourse and the gender violence still recurrent in contemporary times. The results presented here are the result of a historical research, being the analysis based on the theoretical productions of Cultural History. The sources are multiple and come from Oral History through the production of interviews, documentary collection including judicial sources, Cordel Literature, school documents and photographs. The decision to broaden

Esta obra está licenciada sob uma Creative Commons - Atribuição 4.0 Internacional 
the range of sources and analyze them together was due to the thematic complexity and the impetus to build some understandings regarding the impact of discursive construction on the feminine in the symbolic production of women's holiness in that locus. Science, the school, the Criminal Procedure, Literature and the Catholic Church are instruments for the dissemination of values, guide the circulation of ideals and social representations and were important vehicles for the appropriation and representation of the feminine. Despite the various normative and scientific productions that deal with gender autonomy and the social changes that enable greater female performance in the public sphere in recent decades, we observe that in Cariri from Ceará the representation of the feminine is still propagated in a way related to the ideals of nuclear family and the plan of culture is instrumentalized around the values and roles of Gender consolidated two centuries ago. This representative construction contributes to the maintenance of roles and gives vent to gender violence.

Keywords: Gender. Representations. Violence.

\section{Introdução}

A primeira metade do século $X X$ foi um período marcado por uma gênese de movimentos organizados pela emancipação feminina e, ao mesmo tempo, por uma crescente produção científica que tinha por objetivo compreender de forma racional os meandros do comportamento humano e como este poderia ser moldado com fins de que a sociedade chegasse ao patamar de desenvolvimento almejado. Como exemplo, podemos citar, no campo político, a luta pelo direito ao sufrágio, com movimentos que convergiram no mundo todo ao longo de várias décadas, desde o século $\mathrm{XX}$.

Neste artigo, procuramos identificar elementos discursivos comuns sobre gênero em distintos discursos: religião católica, imprensa, Direito; e escola. O intuito é buscar, em alguma medida, aproximações que se relacionem com as narrativas em torno das mulheres santificadas popularmente na região do Cariri cearense.

O processo de santificação popular do feminino no Cariri se construiu historicamente e se relaciona com o discurso penitencial católico e a violência de gênero ainda recorrente na contemporaneidade. Em face de tal realidade, foi possível identificar, na referida região, nove mulheres que sofreram mortes violentas no século $\mathrm{XX}$, as quais são objeto de devoção popular em suas comunidades, tendo a narrativa do sofrimento como justificativa para a santificação (Barreto, 2018).

As representações de gênero, aqui enfocando o feminino, fazem-se e se expõem de modo concatenado às produções discursivas dos variados meios de comunicação e de circulação de ideias. Ao observamos as várias fontes abordadas neste estudo percebemos os valores que se coadunam com o modelo de feminino esperado socialmente. Podemos refletir, assim, sobre como tais modelos influenciam a produção de santidades na comunidade caririense. Para Scott (1990, p. 16) "[...] o gênero é uma primeira maneira de dar significado às relações de poder. Seria melhor dizer: o gênero é um primeiro campo no seio do qual, ou por meio do qual, o poder é articulado".

Sendo o gênero e os elementos que dão significados às distinções entre os sexos (Scott, 1990), ressaltamos que, neste ensaio, quando tratarmos do masculino e do feminino estamos nos referindo a um modelo de conduta historicamente definido, ao falarmos em homens e mulheres nos referimos aos sujeitos cisgêneros. Os resultados aqui apresentados são frutos de uma pesquisa histórica, sendo a análise alicerçada nas produções teóricas da História Cultural. Para tanto, apoiamo-nos nas categorias Representação (Chartier, 1990), Estratégia e Tática (Certeau, 1994). As fontes são múltiplas e advêm: da História Oral, através da produção de entrevistas; de coleta 
documental, contemplando as fontes judiciais, a literatura de cordel, documentos escolares e fotografias. A decisão por ampliar o bojo de fontes e analisá-las conjuntamente se deu diante da complexidade temática e do ímpeto em construir algumas compreensões sobre o impacto da produção discursiva sobre o feminino na construção simbólica da santidade de mulheres naquele lócus.

\section{A ciência e a escola produzindo um modelo}

A família nuclear que se propaga como modelo carece da consolidação dos papeis de gênero para que se cumpra o objetivo de construção do projeto de sociedade higienizada e burguesa. Na mesma medida em que o debate sobre direitos para homens e mulheres se ampliava, a Ciência se ocupava em compreender os espaços de atuação dos indivíduos na sociedade de modo a garantir o famigerado progresso social. A sexualidade se tornou um tema gerador de debates, normativas e políticas públicas amplas que, de certa forma, substituiriam a mal fadada moral cristã para a condução dos comportamentos e deu um ar de cientificidade ao regramento das condutas dos indivíduos, tendo como objetivo o pleno desenvolvimento social. No Brasil, por exemplo, para Araújo e Morais (2014), o debate nacional-desenvolvimentista esteve entre os anos de 1950 e 1960 em confluência com a questão sanitarista, sendo a saúde das populações uma condição/resultado do desenvolvimento.

Assim, ao longo do século $X X$ se multiplicaram os estudos sobre os papéis feminino e masculino e se buscou uma explicação científica para o que durante muito tempo se considerou apenas pecado: caminhamos do espectro do pecado para o da doença. Os comportamentos sexuais se tornaram casos para diagnósticos, e os manuais de comportamento se multiplicaram com base nos estudos científicos. Assim, a Educação feminina também foi influenciada: o "como" ser mulher, mãe e cidadã se tornou um caso para a Ciência elaborar e esclarecer. Podemos citar a análise de Foucault (2014, p. 60) sobre uma Scientia Sexualis que "[...] pretendia assegurar o vigor físico e a pureza moral do corpo social, prometia eliminar os portadores de taras, os degenerados e as populações abastardadas".

A construção de uma ciência que buscasse compreender o sexo para entender o indivíduo, e assim moldá-lo às necessidades da sociedade, passa por um processo de reelaboração em contato com outras instâncias como a moral, em particular, a moral cristã. As fontes e os dados os quais nos dedicamos nesta seção ajudam a construir uma compreensão sobre a circulação de ideias que constituem representações do feminino na região do Cariri cearense em diálogo com o fenômeno de santificação popular de mulheres da região, buscando compreender o impacto dos discursos institucionais e privados nesse processo.

Buscamos documentos escolares do Colégio Santa Teresa de Jesus (Crato-CE); o processo-crime que oficializa o rito penal para a responsabilização dos autores da morte de Filomena Lacerda, uma das mulheres cultuadas como santas na região; exemplares da literatura de cordel, disponibilizados pelo Instituto Cultural do Cariri (ICC); recortes de periódicos datados do século passado, os quais abordam o feminino e, também, disponibilizado para esta pesquisa pelo ICC.

Na primeira metade do século XX, observamos nas escolas um espaço favorável para a aplicação das teorias científicas através das normas médicas e da Pedagogia. Numa fonte coletada no Colégio Santa Teresa de Jesus, escola em que Filomena estudou parte da sua adolescência, observamos as fichas médicas das alunas, em tais 
documentos eram feitos os registros necessários à prática de Educação Física e, percebemos claramente o impacto de uma ciência da sexualidade presente no espaço educacional.

Figura 1 - Ficha de exame biométrico anverso. Colégio Santa Teresa de Jesus (1942).

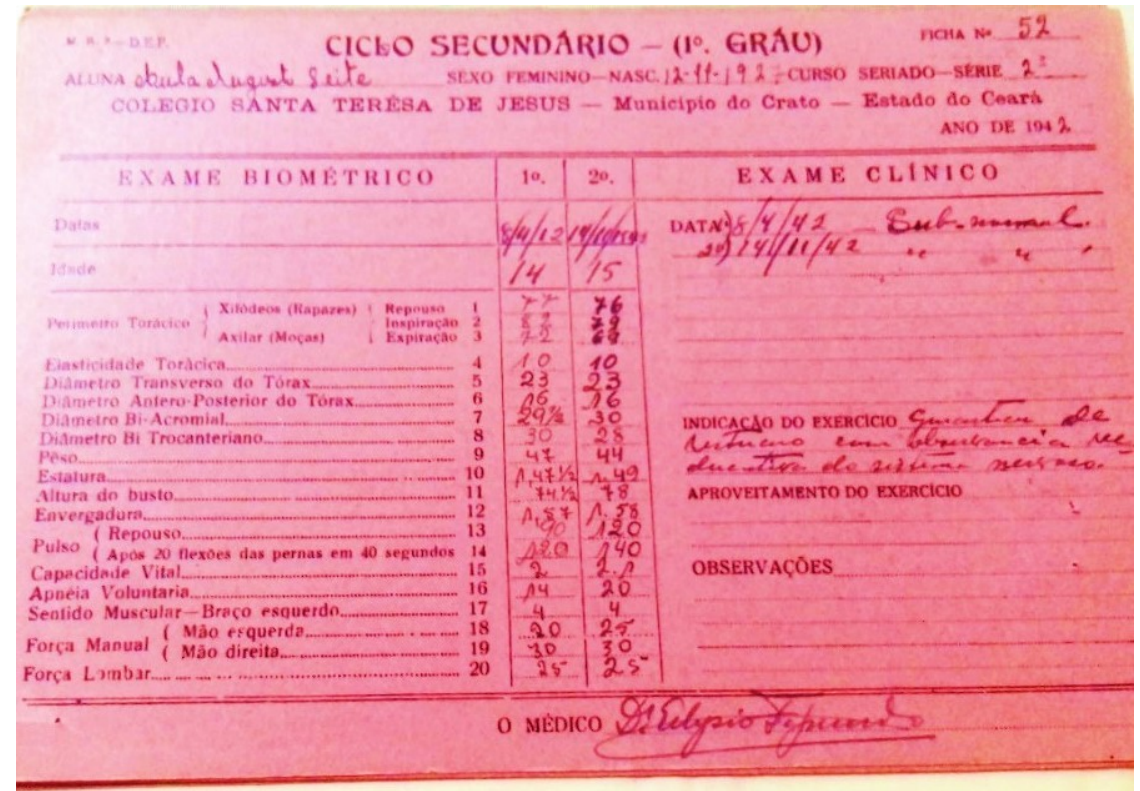

Fonte: (Barreto, 2018)

A fonte acima é um exemplar de ficha de acompanhamento físico de estudantes do Colégio Santa Tereza e data de 1942. Nela, há informações sobre uma aluna ao longo de dois anos, entre os 14 e 15 anos de idade. Observamos a relevância do registro relativo às condições de ordem biológica, constando exames biométricos, clínicos e prescrição de exercício físico.

$\mathrm{Na}$ indicação do exercício físico a ser executado, faz-se referência à reeducação do sistema nervoso, o que nos remete à construção do adoecimento feminino como representação da fragilidade emocional das mulheres proposta pela moral e reforçada pelas ciências médicas na Modernidade. 
Figura 2 - Ficha de exame biométrico verso. Colégio Santa Teresa de Jesus (1942).

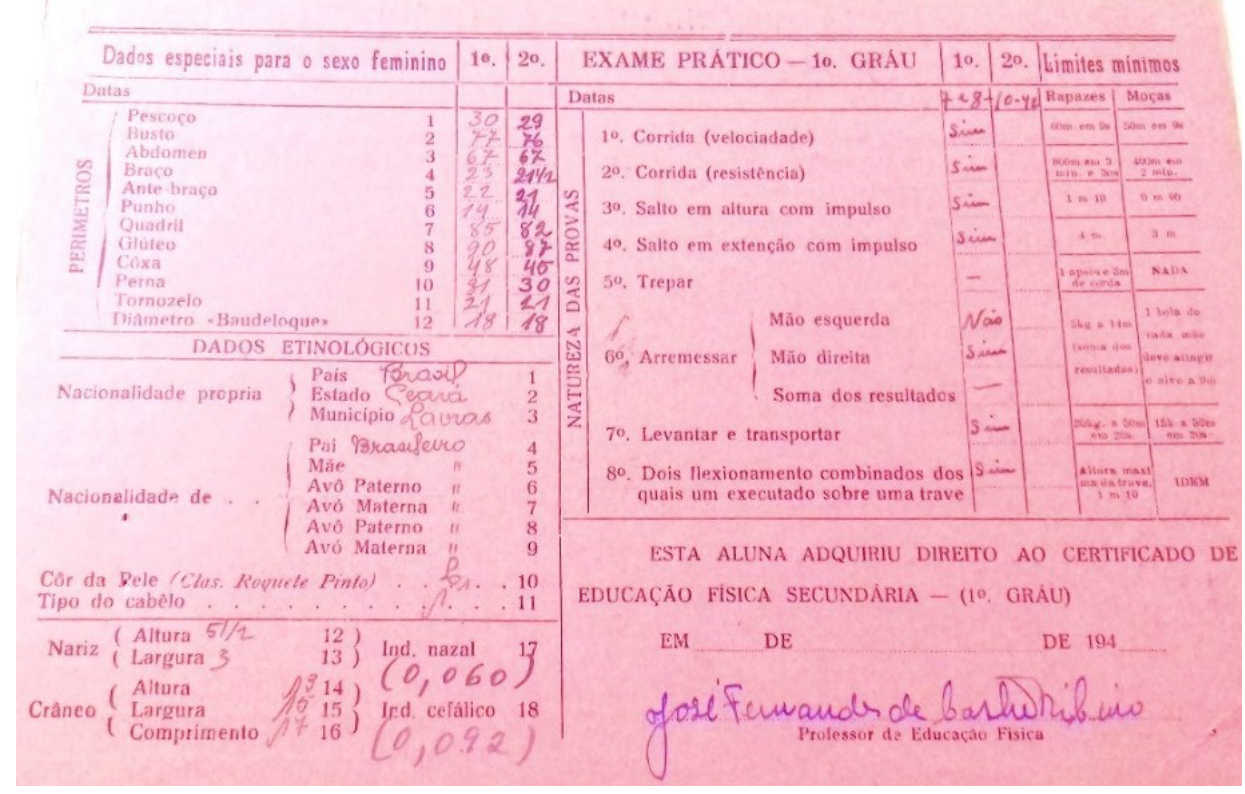

Fonte: (Barreto, 2018)

Foucault (2012) demonstrou os domínios ou estratégias utilizadas para o controle dos corpos e da sexualidade, citando a histerização do corpo feminino, a pedagogização do sexo da criança, a socialização das condutas de procriação e a psiquiatrização do prazer perverso. O corpo da mulher foi analisado, qualificado e desqualificado, conforme aponta o autor, e, nesse sentido, o "nervosismo" se constitui como representação do feminino que carece de cura e controle, diz ele "[...] a Mãe, com sua imagem em negativo que é a 'mulher nervosa', constitui a forma mais visível dessa histerização" (p.113). Ora, se temos na fonte uma prescrição contra o "nervosismo" de uma adolescente de catorze anos, é de se esperar que a educação feminina vise à condução de comportamentos "saudáveis" representados pela mulher tranquila e capaz de cumprir com as suas responsabilidades biológico-morais, sendo assim, adequada ao seu lugar no espaço privado.

No anverso da fonte é possível observar os dados referentes ao caráter etnológico e, ainda, caracterizando um certo eugenismo, na medida em que elenca a classificação Roquete Pinto para a definição de uma "raça". Edgard Roquette-Pinto foi um médico que se dedicou a temas de Antropologia e que no começo do século XX estava envolvido nas discussões acerca da definição do que seria o "brasileiro" a partir de suas características biológicas e culturais. Para o médico e antropólogo, o caminho para o progresso do país estava na "evolução" dos brasileiros através da educação. Assim, a referida classificação estava relacionada aos tipos nacionais definidos pelo médico a partir da cor da pele (Souza, 2012, p. 655).

Roquette-Pinto classificou os 'tipos antropológicos' em quatro grupos principais, seguindo nomenclatura por ele próprio proposta. Para o 'tipo branco', daria o nome de Leucodermos; para os mestiços originados do 'cruzamento' entre brancos e negros, de Phaiodermos; para os mestiços de brancos e índios, de Xanthodermos; para 'tipo negro', de Melanodermos.

Esse é um reflexo da construção teórica em torno do modelo de indivíduo 
adequado à construção da nação. O controle dos corpos é dado na rigidez da fita métrica e no amoldamento dos comportamentos. A educação é vista, assim, como espaço favorável à produção e controle dos sujeitos, criando um cidadão adequado às necessidades sociais e à consolidação do Estado-nação. Nesse sentido, o papel socialmente definido para homens e mulheres ganha um importante espaço nos debates, não apenas no campo da religião, mas, estando presente, também, no espaço da Ciência e, por via de consequência, na escola.

As alunas que ingressavam no curso ginasial do Colégio Santa Tereza tinham aulas de Português, Francês, História, Geografia, Matemática, Latim e Desenho.

Figura 3 - Histórico escolar. Colégio Santa Teresa de Jesus (1942).

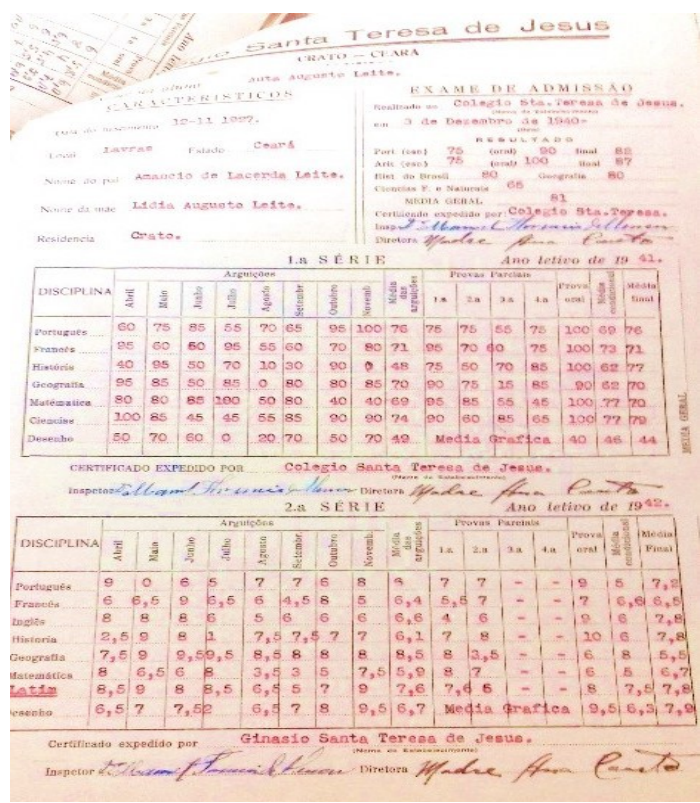

Fonte: (Barreto, 2018)

O estudo institucionalizado na primeira metade do século $X X$ era para as mulheres um importante instrumento para a sua adequação à vida privada no âmbito do cuidado com a família, conforme aponta Arend (2012, p. 72).

\begin{abstract}
Desde o início do século $X X$, a sociedade brasileira esperava que as mulheres desempenhassem novos papéis no âmbito doméstico e na esfera pública. A escolarização em larga escala das meninas estava associada a esse fenômeno econômico. Foi a partir dessa época que as filhas das famílias das elites e dos setores médios passaram a frequentar o curso primário, o ginásio e, eventualmente, o secundário nas escolas confessionais católicas femininas e de outras congregações religiosas nas capitais dos estados federados.
\end{abstract}

O curso primário no Colégio Santa Tereza de Jesus se dava de acordo com a instrução pública de estado, conforme normas estabelecidas. O ensino secundário durava quatro anos e o normal mais dois anos. Nesse período, eram ofertadas as cadeiras de Psicologia, Pedagogia, Sociologia Educacional, Técnica do Ensino, Higiene Geral e Puericultura (Goiana, Queiroz, 2013). A formação de professoras vai ao encontro da formação das mães da República, aquelas responsáveis pela formação dos cidadãos.

Paulatinamente, são abertas escolas no interior do país e é notória a participação de instituições para a educação das moças nesses locais. São, geralmente, escolas 
mantidas por congregações religiosas que tratam da formação das mulheres, primeiramente para o desenvolvimento de suas habilidades no âmbito privado ou as preparam para a vida consagrada.

O Projeto que culminaria com o Decreto-lei 3.200, de 19 de abril de 1941, que foi promulgado quando Filomena contava com dezesseis anos, definia para o Estado o papel de educar a infância e a juventude para a família:

Devem ser os homens educados de modo que se tornem plenamente aptos a responsabilidade de chefes de família. Às mulheres será dada uma educação que as torne afeiçoadas ao casamento, desejosas da maternidade, competentes para a criação dos filhos e capazes na administração da casa. (Art. 13) (Schwartzman, 1981)

O texto do projeto claramente informa que haverá a produção de papéis e o fortalecimento da representação de um destino biologicamente traçado e, por isso, socialmente aperfeiçoado. Desse modo, seriam homens e mulheres destinados aos papéis de líder do núcleo familiar e de cuidadora, respectivamente, sendo a educação responsável por tal amoldamento.

\section{Violência de gênero: entre os documentos judiciais, a oralidade e a poesia}

Não apenas documentos escolares ou legislativos expõem as representações de gênero, os textos judiciais também oferecem uma boa oportunidade para esmiuçar esses elementos. Ao analisar o processo-crime referente à morte de Filomena Lacerda, uma das mulheres cultuadas como santas na região do Cariri, observamos a presença de outra mulher colocada em evidência na comunidade, mas, exposta institucionalmente nos documentos oficiais sem nenhuma dignidade. Trata-se da amante de Manoel Nazário, consorte e assassino de Filomena. A garota retratada na fonte tem, a época do crime, dezoito anos, enquanto Manoel conta com sessenta e três anos e Filomena cinquenta anos. A jovem é coautora do homicídio, sendo a mesma quem desferiu os golpes que levaram Filomena à morte, sob orientação de Manoel Nazário. Considerando os aspectos éticos, nomeamo-la de Maria, a fim de preservar a sua identidade, já que a mesma não retornou à Cidade de Mauriti desde o fim de sua prisão, residindo, segundo nos contou alguns familiares, em outro estado. Maria é representada verbalmente nos discursos das fontes orais como a amante, a outra, e, até, nos documentos oficiais como, é o caso do processo crime. Em vários trechos seu nome sequer é explicitado, apenas as características que a identifica na fonte como o oposto daquilo que é socialmente esperado. 
Figura 4 - Denúncia. Processo-crime (1975).

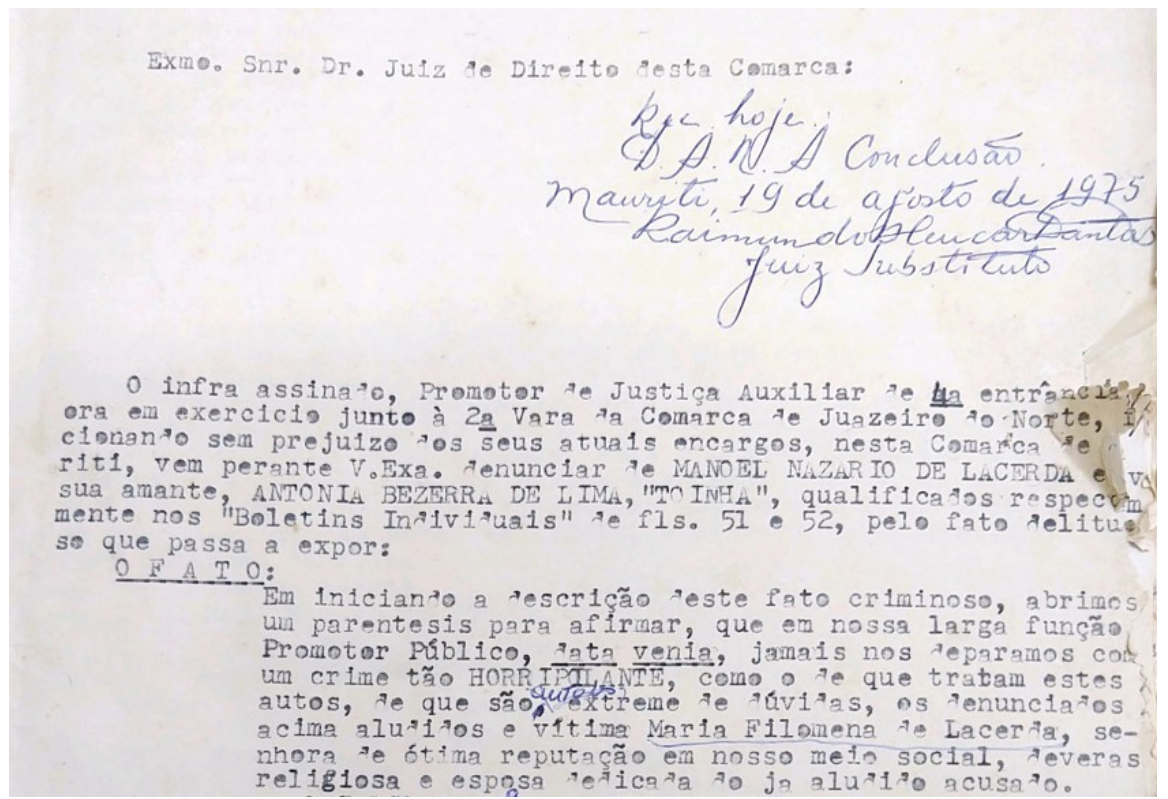

Fonte: (PROCESSO-CRIME, 1975)

A primeira página da denúncia do Ministério Público (MP-CE) ao Judiciário da Comarca de Mauriti, por ocasião da morte, trata de anteceder à identificação civil da coautora do crime, como o qualitativo amante. Ao mesmo tempo, a vítima do crime é, também, socialmente determinada, qualificada como "senhora de ótima reputação em nosso meio social, deveras religiosa e esposa dedicada [...]". O feminino não escapa à representação explícita com papeis bem delimitados. A fonte nos oferece elementos que dicotomizam o feminino a partir da representação explicitada.

Sendo o MP-CE responsável legal pela acusação na esfera penal, e diante de um homicídio doloso que é julgado pelo Tribunal do Júri, observa-se o esforço discursivo pautado no convencimento dos jurados em toda a peça de denúncia. Adjetivos como horripilante para o crime, palco sangrento para o local do assassinato e a interjeição de teor religioso proferido pela vítima quando se percebe em perigo, são observados na peça na mesma medida em que se consolida o discurso binário entre as duas mulheres.

A peça do interrogatório de Manoel Nazário é, também, uma fonte relevante para refletirmos acerca do status do feminino na década de 1970, bem como os elementos representativos do feminino profano que se apresentavam como aqueles dotados de competência para iludirem e seduzirem, conforme observado nas representações de Eva no imaginário social e nos textos cristãos. O interrogado ressalta o poder de Maria para convencê-lo a iniciar com ele uma relação amorosa. Nesse aspecto, apresenta-se, discursivamente, como desprovido de capacidade de escolha, apresentando-se como sujeito iludido. A peça destaca que a jovem, que então contava com quinze anos quando do início do relacionamento, "[...] passou a iludir o declarante, até quando o mesmo caiu na conversa [...]". 
Figura 5 - Peça de interrogatório (1975).

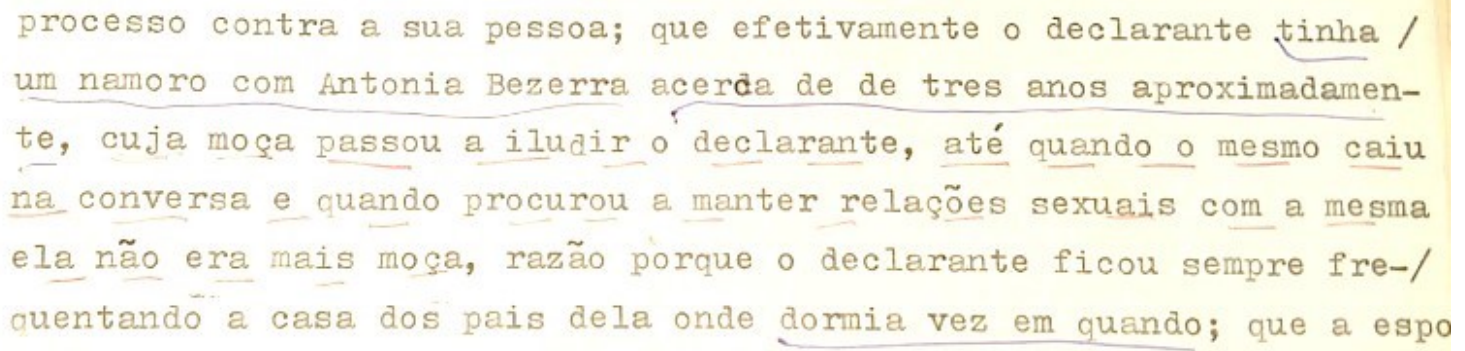

Fonte: (PROCESSO-CRIME, 1975)

Esse aspecto se consolida ao compararmos com as fontes orais construídas na pesquisa. Ao tratar de traição e fidelidade, o masculino é retratado pelas mulheres entrevistadas nesta pesquisa como o sujeito frágil diante de investidas do feminino, sendo a mulher quem é qualificada como a outra, sendo, ainda, representada como aquela sujeita capaz de enfeitiçar. A partir de um diálogo entre duas mulheres residentes em Mauriti, cidade onde ocorrem os eventos rituais em honra à Filomena, como romarias e celebrações eucarísticas, gravado sob concordância das duas e que tem como tema as dificuldades conjugais, as posições binárias entre a mulher casada, que cuida do matrimônio, e a mulher amante, que interfere e é responsável pela instabilidade da relação é nítida, percebemos que o feminino que se encontra fora da relação institucionalizada no discurso da esposa entrevistada, seria responsável, até mesmo, pelo envolvimento do masculino com drogas ilícitas, o que coloca sua integridade física em risco. Conforme se observa no trecho a seguir, o homem é fácil de ser iludido, diz uma das entrevistadas.

$(E 1)^{1}$ - É difícil e principalmente desse tanto de ano de casado, ê! É difícil demais. Separe não dona T3, continue sua vida com seu marido já superou tanta coisa, bota essa mulher pra correr.

(E2) - O povo da rua disse: minha fia tire seu marido daí ele vai morrer, tô com pena. Foi uma crente, mulé, tu acredita? Já essa semana eu tava conversando com uma mulé lá dessa rua.

(E1) - Ele não vai deixar a senhora por essa mulher não, isso é só ilusão de homem, porque homem é fácil de ser iludido. (Barreto, 2018, p. 165)

Caberia ao feminino, por sua vez, a manutenção da relação e a superação das dificuldades. Essa é uma Representação (Chartier, 1990) exposta pela fonte, ao mesmo tempo uma Estratégia (Certeau, 1994) construída discursivamente ao longo do tempo com amparo na religião e na ciência e que oferecem as bases necessárias à assimetria nas relações de gênero. Esse papel, construído historicamente e consolidado por ocasião da formação da família burguesa, ainda se mantém no Cariri de maneira heterogênea, como são os fenômenos sociais, mesmo diante das mudanças sociais no tocante às relações de gênero.

A luta pela manutenção do matrimônio se atualiza na fala das entrevistadas e vem ao encontro de outro trecho da peça interrogatória que trata do fato de Filomena, apesar de ser sabedora das relações do marido fora do casamento, refugiar-se distante da Zona Urbana para evitar estar em contato com a questão. Essa informação é, também, ressaltada nas fontes orais como uma atitude típica da boa esposa e mulher dedicada, papéis sociais atribuídos ao feminino no contexto do assassinato e ainda

${ }^{1}$ E1 e E2 para primeira e segunda entrevistadas, respectivamente. 
ecoando nos discursos contemporâneos, conforme se observa a seguir:

[...] o declarante continuava a namorar com a mesma, razão por que sua esposa procurou ir morar no campo, afim de não ter aborrecimentos futuros; e como nada mais disse e nem the foi perguntado, deu-se por findo suas declarações [...]. (Processo-Crime, 1975, p. 10)

E42- Depois daqui da rua ela foi morar no Carretão, lá onde ela faleceu, até ela morava numa casinha mais pra cá, mais próximo, depois ela foi, exigiu ficar na casinha mais perto do curral do esposo dela pra que ela fizesse o cafezin dele mais cedo pra ele tomar lá.

P- Então foi um pedido dela mudar pra essa casinha mais simples?

E4 - Sim, foi um pedido dela, mudar pra essa casinha mais simples pra que ela tinha acesso de fazer o lanchin dele mais cedo pra ele conseguir ir pro trabalho dele e tirar o leite. (Barreto, 2018, p. 165)

Na medida em que tal atitude é representada como modelo, apresenta-se como tática (Certeau, 1994) daquela mulher para se proteger diante da humilhação da traição pública, ao mesmo tempo o marido era obrigado a se manter afastado, tanto quanto possível, da Zona Urbana e do acesso à Maria. Não se apresenta na fala das entrevistadas uma demanda pessoal, tampouco o mal-estar pela imposição das regras sociais que se concretizam com a manutenção do casamento, o qual não parece ser minimamente harmônico, tanto que culmina em um ato de violência letal. Por outro lado, contemporaneamente, observam-se os elementos da santidade atrelados aos valores da doação. A mulher que doa o seu tempo ao cuidado familiar, à submissão, considerando a reclusão para evitar constrangimentos e a modéstia representada pela morada muito simples, apesar de ser uma mulher de posses, vai ao encontro do ideal de santidade propagado para o feminino.

Ainda no processo-crime, um suspeito que é excluído da denúncia por ausência de provas dá conta dos motivos pelo quais Filomena deixou a Zona Urbana onde vivia próxima dos familiares para residir na Zona Rural em local ermo e distante do núcleo urbano.

[...] numa certa ocasião ouviu dizer que estava com vontade de botar sua mulher legítima no sítio, para alí morar uns tempos e depois a trazia de retorno a esta cidade; [...] não encontrou a mulher de Manoel Nazário na casa verdadeira e sim noutra toda deteriorada [...] Filomena Augusto de Lacerda, a qual limitava-se ainda naquela época o costume de rezar constantemente como fazia anteriormente; que o xodó existente entre Manoel Nazário e Maria ${ }^{3}$ cunhada do declarante, vem a cerca de três anos, sendo um caso esclarecido por todos tanto da cidade como dos sítios vizinhos. (Processo-Crime, 1975, p. 12)

Ao tratar dos motivos que levam a vítima a viver reclusa, surge na fonte a afirmação de que tal decisão seria do marido. Esse dado trazido pelo documento escrito datado anteriormente à construção das fontes orais se mostrou para nós relevante. $O$ discurso do feminino na contemporaneidade apresenta ora uma mulher dedicada que busca a Zona Rural para estar mais próxima do esposo e assim cumprir os deveres instituídos com o matrimônio, ora é retratada como a mulher que prefere se refugiar distante dos olhares da comunidade para não ter acesso às informações relativas ao

\footnotetext{
${ }^{2}$ E4 para quarta entrevistada e $P$ para pesquisadora.

${ }^{3}$ Nome fictício a fim de resguardar a identidade de co-partícipe no crime, em vista de ser uma pessoa que ainda está no convívio da comunidade.
} 
relacionamento que o esposo mantivera fora do casamento, delineando-se, assim, a representação da esposa que toma decisões, apesar de difíceis, com fins de proteger o instituto do matrimônio.

Não aparece em nenhuma das entrevistas algo referente à mudança de domicílio ter sido uma decisão do esposo. Nesse sentido, compreendemos que o modelo de feminino apropriado pela comunidade, a partir do advento da santificação popular de Filomena, contribui para a manutenção dos valores da feminilidade, historicamente constituídos, considerando as instâncias religiosas e educacionais.

O contexto do depoimento acima é dramático, o sujeito que fala está sendo suspeito de assassinato. Apesar de não apontar outros indivíduos que pudessem ser autores do fato, relaciona de modo interessante as características sempre presentes nas demais fontes, a relevância da vivência religiosa para a mulher. Filomena, segundo o registro, limitava-se à prática religiosa como "fazia anteriormente". Antes de se mudar para o Sítio Pereiros, Filomena se dedicava ao trabalho pastoral na Paróquia de Nossa Senhora da Conceição em Mauriti. Após a mudança, continuou com as atividades religiosas, ministrando catequese para crianças da Zona Rural. Nas imagens que seguem, podemos vê-la em eventos religiosos dessa comunidade.

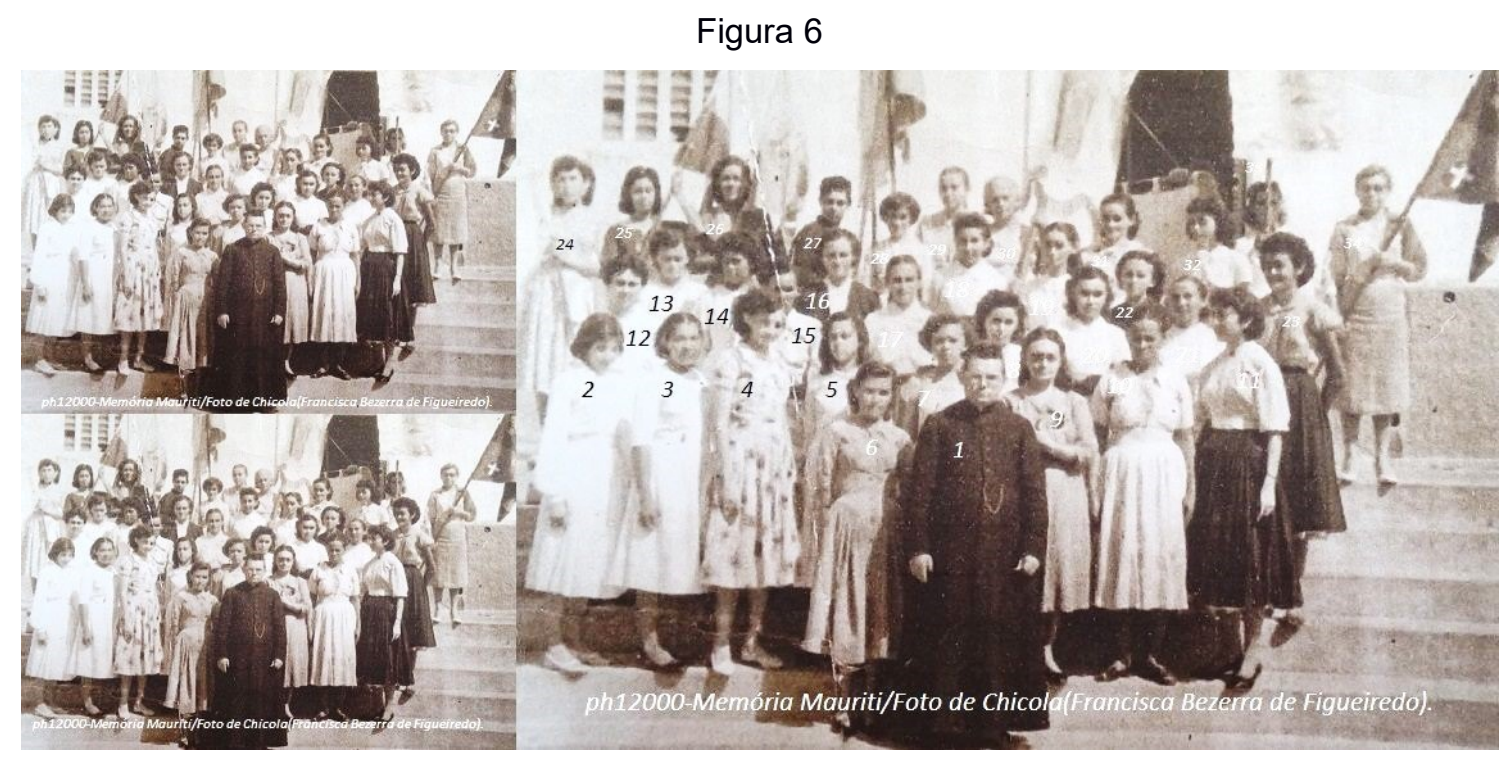

Fonte: ${ }^{4}$ Site Memória Mauriti (2017)

Padre Valdir, numerado na imagem e em primeiro plano, foi Vigário na Paróquia de Mauriti e conduzia, junto com a comunidade, o trabalho pastoral. O Padre Argemiro, que o sucedeu, foi, além de pároco, confessor de Filomena e seu amigo pessoal. Após a morte dessa, o próprio Padre Argemiro testemunhou eventos miraculosos ocorridos.

Em certa ocasião, durante uma viagem do Padre e por se encontrar em lugar ermo e com o veículo sem combustível, após uma prece à alma de Filomena, a própria teria ido ao seu encontro munida de um vasilhame com o combustível necessário para que o sacerdote completasse o seu percurso. Essa narrativa compõe o conjunto de memórias da comunidade local e consta no livro de testemunhos existente na capela erguida em homenagem à Filomena no local de sua morte.

\footnotetext{
${ }^{4}$ Ordem de apresentação das imagens: 1/Padre Valdir, 2/lolanda Saraiva, 3/Dona Licor, de Zé Vicente, 4/Terezinha Pimenta, 5/, 6/Ancila Domini, 7/, 8/, 9/Filomena
} 
Figura 7 - Grupo missionário de Mauriti. Filomena Lacerda II.

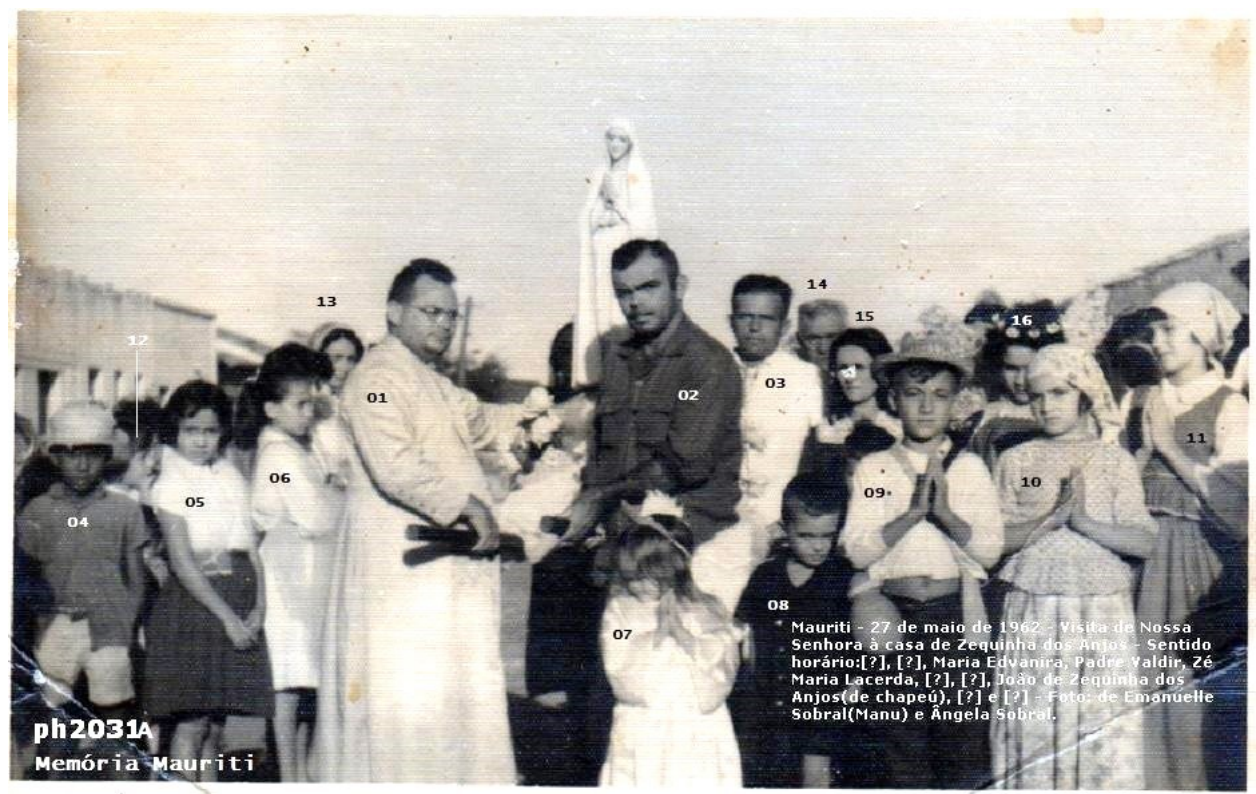

Fonte: Site Memória Mauriti ${ }^{5}$.

Essa participação, de certa forma, cria um contexto que compreendemos fazer frente às dificuldades encontradas na esfera privada. Ao se dedicar à atividade missionária, Filomena ganha um espaço público de notoriedade que enaltece características e valores de relevância social naquele período e naquela comunidade. O modelo de família nuclear, ainda preponderante atualmente, e norteador das relações sociais no período em estudo nesta pesquisa, constitui-se o contexto de vivência das mulheres retratadas neste relatório.

A atividade fora do eixo familiar se mostra uma Tática (Certeau, 1994) para romper os limites do papel devido ao feminino na esfera privada. O trabalho de catequista desenvolvido por Filomena a coloca em um espaço comunitário privilegiado e alternativo à vivência exclusivamente familiar. Ao atuar como educadora com fins de propagar a dimensão católica na comunidade Filomena se consolida como sujeita de poder simbólico, reconhecida naquele território e respeitada como mulher capaz que tem algo a dizer, considerando a sua atuação missionária.

Em 1975, ser catequista e manter a oficialidade do matrimônio eram dimensões diretamente relacionadas. Assim, não seria coerente para a Igreja Católica a falência matrimonial de uma missionária, a despeito do que é normatizado pelo Código de Direito Canônico (1997). Tal regra não tinha em 1975 nenhuma aplicabilidade prática ou divulgação.

Cân. $1153-\S 1$. Se um dos cônjuges provocar grave perigo da alma ou do corpo para o outro ou para os filhos, ou de algum modo tornar a vida comum demasiado dura, proporciona ao outro causa legítima de separação.

Ao tratarmos acerca da atuação comunitária de Filomena, uma das entrevistadas levanta aspectos das dificuldades que poderiam ser encontradas para a atuação

${ }^{5}$ 01-Padre Valdir Sobreira Leite, 02-Zé Maria de Lacerda, 03-Jomar Lacerda (irmão de Zé Maria), 04, 05, 06-Maria Edvanira Cartaxo, 07-Corrinha (filha de Jomar), 08-Tião (filho de Jomar), 09-João (de Zequinha dos Anjos), 10-Dilzinha (de Chico Alves), 11, 12, 13-Filomena Augusto de Lacerda, 14-João Augusto de Lacerda (pai de Zé Maria e Jomar) 
missionária em face de uma dissolução conjugal.

(P) - Por que ela não se separou do esposo, considerando os problemas na relação?

(E5) - É porque é assim: ainda hoje existe muito preconceito, imagine na época, 1975, uma pessoa separada. Eles não perguntavam porque ela estava separada, só ia ser taxada como uma pessoa separada, né, infelizmente isso tinha muito peso e eu acho que por conta da função dela na Igreja, desse envolvimento com a Igreja ela decidiu ficar aguentando. Quando ela mandou uma carta pra mãe dela, não sei se você teve acesso a uma carta, ela dizia que a vida dela não era fácil, era sofrida, chegou a comparar, se não me engano, com o purgatório, de tanto sofrimento que ela passava, né, então aguentar aquilo tudo foi por conta disso também pra não ser taxada como isso, pra permanecer ali num ambiente que ela se sentia bem que era onde ela procurava ajuda e onde ela era amparada não é? Onde ela tinha os amigos, acredito que tenha sido por isso, também. (Barreto, 2018, p. 169)

Filomena não teve filhos. No seu depoimento nos autos do Processo-crime, Manoel Nazário considera uma possível incompatibilidade biológica entre os dois, somado a isso o fato de a mesma ter se submetido a sucessivas cirurgias, do discurso se alude que essas seriam as justificativas para a ausência de prole. Havia uma lacuna no modelo familiar esperado. Na perspectiva da família nuclear, a ausência de descendentes ampliava a possiblidade de atuação fora do ambiente doméstico. Assim é que muitas das pessoas com as quais nos encontramos por ocasião do trabalho de campo afirmam terem sido catequizadas por ela.

Figura 8 - Peça do interrogatório II (1975).

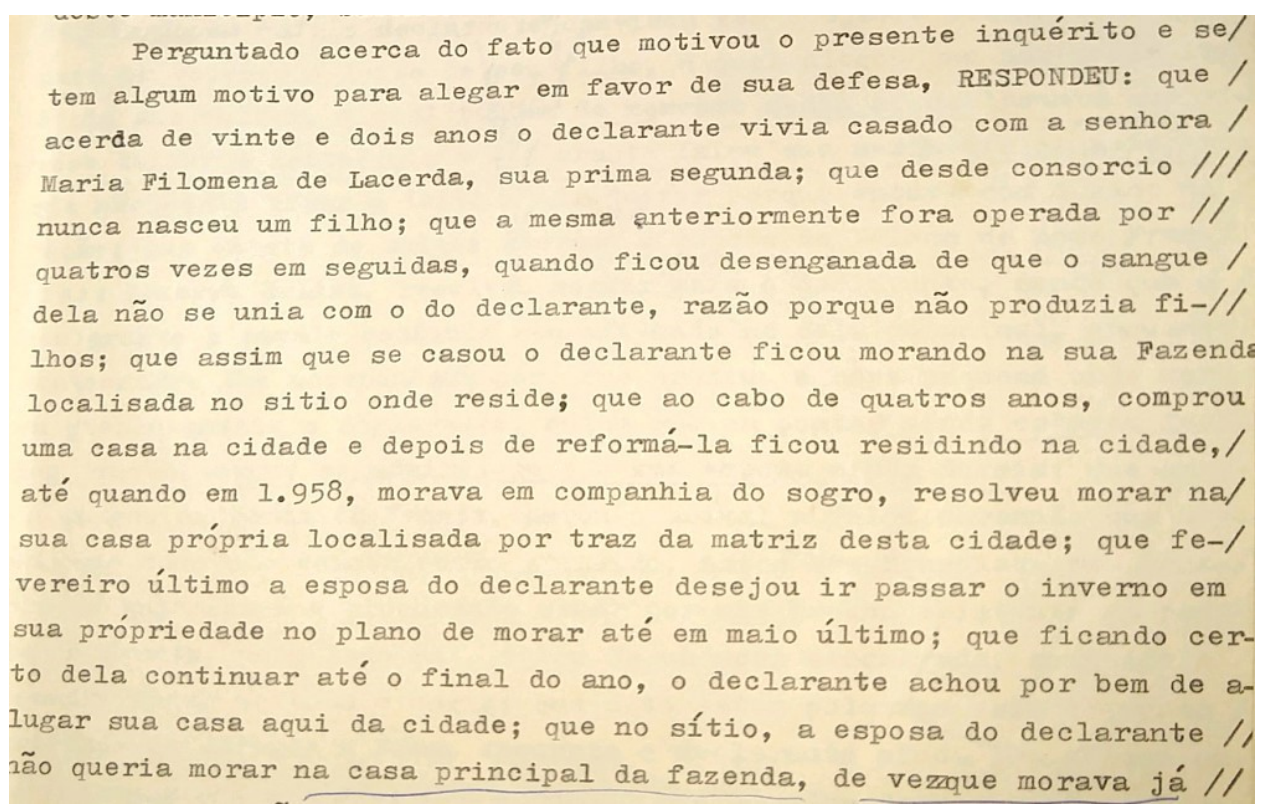

Fonte: (Processo-Crime, 1975)

Do ponto de vista das representações, Filomena poderia ser exemplo de mulher fracassada no âmbito da empresa familiar. Não conseguiu, à luz das normas sociais, exercer o papel fundamental do feminino: ser mãe. Logo, não foi capaz de pôr em prática as atividades dos cuidados maternos, tão caros à divisão sexual de tarefas propagadas pelas ciências das primeiras décadas do século XX. Restou à sensibilidade de Filomena se ocupar do cuidado dos filhos dos outros. $O$ trabalho de catequese se configura como a transferência de sua atividade primordial materna. Daí a relevância com que a mesma 
desenvolve o trabalho catequético, mantendo-o, apesar de sua mudança domiciliar para um reduto na Zona Rural, distante da matriz paroquial da Cidade de Mauriti, onde costumava desenvolver as suas atividades.

A representação de Santidade presente no discurso dos entrevistados dá conta de uma mulher que tudo fez pelo trabalho pastoral, mas, na via de uma análise mais apurada, podemos elaborar uma reflexão em torno do poder de decidir o rumo de sua vida social. $\mathrm{O}$ trecho do depoimento a seguir apresenta um feminino que se empodera frente ao masculino, demonstrando aspectos da fragilidade do poder desse no âmbito privado.

(T1) Disse que ele dizia: - Filomena, deixe disso, Filomena. Pra ela num tá rezando com os meninos, aí ela dizia: Não, Manuel, deixa que é meus santo, enquanto eu tiver com esses santinho aqui eu tô feliz, é meus santo, num se importe não, basta cuidar de você mesmo, de seu trabalho, deixe que eu cuido de meus santin. (Barreto, 2018, p. 170)

A vinculação ao trabalho pastoral dava à Filomena um espaço privilegiado em que a mesma não possuía na esfera privada. Sendo traída de forma reiterada pelo marido, sem ter tido prole a ser cuidada, a Igreja se constitui o espaço de significado social para essa mulher.

A fonte referente ao interrogatório de Manoel Nazário leva à reflexão dos papéis de gêneros circunscritos ao período em que se produz a fonte. A primeira informação relatada pelo declarante diz respeito ao fracasso familiar frente à ausência da prole. Vêse que ao tentar relatar os motivos do crime, Nazário inicia o seu discurso demonstrando que, apesar dos mais de vinte anos de convivência, nunca tiveram filhos. Ademais, foi recepcionado nas terras do pai da esposa, tendo-os adquirido residência somente após quatro anos.

Tal aspecto pode ser relacionado com a fragilização dos valores atinentes à virilidade do feminino. O masculino, nesse caso, aparece castrado de sua função de provedor pelo feminino, bem como acaba por ter a sua capacidade de procriar posta em xeque. Assim, observa-se o esforço do depoente em encontrar justificativas para a inexistência de filhos no corpo do feminino e não o contrário.

Ao triangular as fontes com fins de tratar da circulação de ideias acerca do feminino, observamos que a fonte judicial não está dissonante das fontes literárias regionais. A literatura de cordel, fortemente produzida e disseminada no Cariri cearense, representa o feminino de forma consonante aos demais documentos analisados.

A poesia caririense da primeira metade do século $X X$ nos dá elementos para refletir sobre as representações de Gênero no território do Cariri e, nessa perspectiva, os espaços de afeto e disputa. A rima de Pedro Bandeira (1975), poeta popular do Cariri, apresenta um triângulo amoroso e o masculino seduzido, assim como é apresentado nas fontes orais produzidas e analisadas até aqui, bem como o discurso judicial constante nas peças do processo penal em análise. Um masculino inerte às tentativas femininas de conquista salta aos olhos, também, nas fontes literárias coletadas.

O confronto se apresenta entre o feminino em disputa pela proteção e virilidade do macho, deixando transparecer a dependência e o lugar dos sujeitos e a sua função social a partir do gênero. O poema "Deixa meu Amor de mão", publicado no Cariri e em circulação na região na década de 1970, é um monólogo dirigido à amante do marido por parte da esposa. A fonte foi coletada nos arquivos do Instituto Cultural do Cariri (ICC). A dita mulher de bem aparece no discurso defendendo o seu núcleo privado, 
espaço privilegiado de sua responsabilidade social.

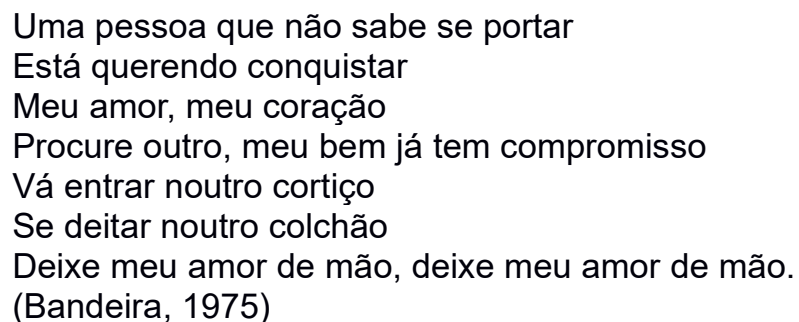

A pessoa que não sabe se portar se refere àquela que, quebrando as regras, opõe-se ao comportamento feminino considerado coerente e correto. Dessa forma, ao desejar compor um relacionamento extraconjugal, seria a mulher culpada pela desarmonia matrimonial, sendo aconselhada a desistir das intenções amorosas em face de um vínculo conjugal precedente. Deixe meu amor de mão sintetiza a conduta ativa da mulher que invade o espaço privado matrimonial e eleva a conduta passiva do masculino, que, conforme o poema, constitui-se como sujeito que sofre a ação de ser conquistado.

Nessa perspectiva, observamos, de forma reiterada, a representação da potencialidade narcísica das mulheres que salta do espaço religioso para a instância da Ciência, assim como na dogmática cristã. O feminino eivado de uma excessiva sexualidade se apresenta, de forma perigosa, à empresa familiar na modernidade. Diante disso, o dispositivo de controle se reelabora de forma a manter o domínio do corpo feminino e a submissão deste à famigerada racionalidade do masculino.

O eu lírico apresenta razões de ordem econômica com fins persuasivos em relação à concorrente, fazendo-a desistir do seu intento, inserindo a dependência financeira como preocupação diante da possibilidade de um caso extraconjugal. Tratase, assim, mais do que a mera defesa da unidade familiar, sendo, contudo, a defesa de sua própria sobrevivência. Defender o matrimônio chega a se apresentar como resistência à indigência, numa sociedade que ainda propaga a função feminina como aquela de dependência social e econômica em relação ao masculino, em um cenário de ausência de direitos sociais para as mulheres, garantia de emprego e renda ou proteção contra a violência.

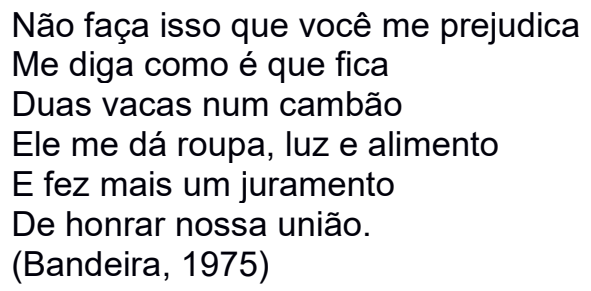

Nesse verso, observa-se um apelo e não uma ordem, na medida em que apresenta as dificuldades concretas para a manutenção de uma nova ordem conjugal, ao mesmo tempo o peso do juramento sacramental aparece no discurso como aspecto normativo a ser considerado. Nos versos a seguir, o masculino apresentado pelo eu lírico feminino como passível de persuasão e de ser conduzido ao erro sem possiblidade de escolha, demonstra a representação da Eva do Pecado Original Cristão. A mulher é, a partir da canção popular, o único elemento responsável pelo que é considerado, do ponto de vista formal e normativo, uma anomalia social, qual seja a traição conjugal. 
Você botando fumo na cabeça dele

Está dando conselho a ele

Pra fazer-me ingratidão

Procure outro que esta boca é muito quente

Vá ligar outra corrente

Apertar noutro botão.

(Bandeira, 1975)

Termina o poeta por apresentar os traços do catolicismo popular, apelando para o espaço do sagrado a fim de dar cabo dos problemas materiais que se colocam no cotidiano dos indivíduos, mas, que ao mesmo tempo, comunica-se com o campo dos afetos. O que fazer para salvaguardar um relacionamento que, além de garantir a manutenção da função social do feminino numa dada comunidade, ainda visa à sobrevivência material do corpo? O masculino, disputado pelo eu lírico, seria, conforme aponta o discurso, provedor dos bens materiais da família.

Devemos ressaltar que, ainda que consideremos a existência, ao longo dos séculos no Ocidente, do trabalho feminino gerador de renda e riquezas, esse não é caracterizado discursivamente como digno de nota numa estrutura patriarcal. Apelos, agradecimentos e orações são as táticas utilizadas pelo eu lírico para fazer frente à traição conjugal, bem diferente de muitas das práticas observadas no Cariri cearense por parte do masculino, quando a quebra do contrato nupcial se dá por parte do feminino.

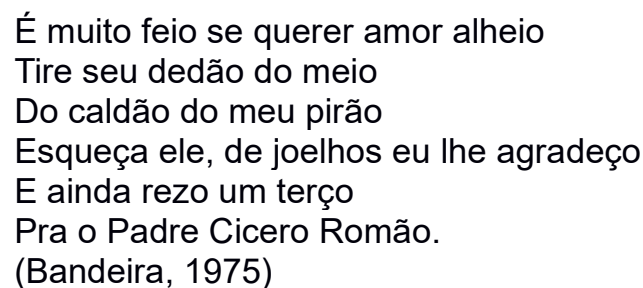

Analisada em paralelo com as fontes orais, podemos afirmar que a representação do feminino ora sedutor, ora protetor dos laços conjugais, e de um masculino passivo, mantém-se na construção discursiva contemporânea, como se apresenta, também, a busca pelo divino na superação das dificuldades conjugais, além do culto à representação do feminino que supera tais dificuldades. Os relatos orais sobre Filomena e sua postura no âmbito do matrimônio dialogam com nossas afirmações.

(T1) - Ela não pensava em separar não, porque quando o povo vinha dizer ela dizia era assim, que não se preocupava com ele não, chamava ele era meu santo.

(T5) - Muitas pessoas em Mauriti que conseguiram graças com ela pelo martírio dela, segundo o pessoal conta, ela era catequista e disse que aceitava, era da igreja, aceitava as traições sem dizer nada, do esposo que traia ela e tanta coisa errada e aceitava, ele matou.

(T6) - Nós temos uma alma santa e a igreja precisa ter conhecimento disso. Quem tá aqui hoje é que tem que lutar pra levar ela à canonização, diante do seu martírio, de sua história de vida, que nunca fez mal pra ninguém, dedicada a Deus, servir de exemplo pra essas que tão sofrendo, né não? Que, às vezes, são até mártir também, servir de modelo, tem muitas que sofrem, tem muitas. (Barreto, 2018, p. 174)

Como afirma Saffioti $(2004$, p. 78) "No grupo domiciliar e na família não impera necessariamente a harmonia, porquanto estão presentes, com frequência, a competição, a trapaça e a violência". Em acordo com a autora, observamos a disputa 
pautada pela territorialização simbólica do domínio, o papel viril do pai ameaçado pelo filho apresenta as lutas de poder que formatam a família patriarcal na primeira metade do século $X X$.

$\mathrm{Na}$ família, especialmente, registra-se o maior impacto da violência simbólica e física no âmbito da relação de gênero. Nesta pesquisa, registramos eventos violentos ocorridos no espaço privado da família que chama a atenção para o debate da construção das representações e papéis de gênero que perpassa variadas instâncias sociais, mas que tem na família um lugar privilegiado. A esse respeito, Bourdieu (2014) afirma que, no século $X X$, as três principais instâncias de reprodução da ordem dos gêneros são a Família, a Igreja e a Escola, as quais, de forma orquestrada, atuam sobre as estruturas do inconsciente. Contudo, "[...] à Família, que cabe o papel principal na reprodução da dominação e da visão masculina, é na família que se impõem a experiência precoce da divisão sexual do trabalho e da representação legítima dessa divisão, garantida pelo direito e inscrita na linguagem" (p. 120).

Saffioti (2004), ao discutir Patriarcado e Violência, chama a atenção para um elemento interessante que vai ao encontro do debate acerca do impacto das representações de gênero no cotidiano. O poder apresenta duas faces, pelo menos: a da potência e a da impotência. O masculino não foi socializado para lidar com a impotência, com o fracasso, com a perda de domínio sob qualquer hipótese. No caso, em tela, o pátrio poder parece estar em xeque duplamente: em relação à mulher, que, ao dispor do próprio corpo, representa para o masculino a perda do domínio sexual e de sua própria virilidade; e, sobre o filho, institucional e simbolicamente vinculado à figura paterna.

\section{Considerações finais}

Os temas da família, dos afetos e da sexualidade ganham as escritas educacionais, judiciais, os periódicos e a poesia. Diante dessa observação, defendemos a relevância da variedade de fontes na pesquisa histórica que visa a uma análise de representações. A traição, os feitiços de amor, o perdão amoroso e as relações familiares ganham relevo nas fontes e demonstram as ideias construídas sobre os papéis sociais esperados para homens e mulheres.

Os dilemas afetivos narrados pelo eu lírico, a partir da invenção criativa de um homem hétero que vive e faz poesia popular no território do Cariri na primeira metade do século $X X$, o discurso estatal que dicotomizou o feminino sagrado e o profano no processo-crime em análise, os documentos escolares que apresentam o controle institucional do corpo feminino nos oferecem indícios acerca das representações de gênero no século passado e nos ajudam a compreender o contexto social onde se desenrolam as tramas de violência e santidade tratadas naquela localidade.

A rigidez da dominação de um gênero sobre o outro, de forma dicotômica, impacta todas as estruturas sociais, determinando o lugar de cada indivíduo na organização social. Assim, o espaço privado continua, a despeito dos debates que se colocam atualmente, organizado sobre a égide da diferença de gênero em face das funções que se entendem adequadas para cada variável. Assim é que se faz necessário o debate histórico acerca dessas construções simbólicas sobre o gênero.

Na narrativa católica, a punibilidade do agressor é substituída pela consolação divina. O fortalecimento da ritualística do sacrifício se dá na medida em que se constrói um percurso naturalizado para a vida, a morte e o processo de divinização da mulher. 
As tensões sociais são explicadas à luz do místico, levando a construções de representações que, de um lado contribuem para cristalização de uma aparente paz social em face da justiça divina que se aplica aos casos de violência e santificação abordados neste trabalho, e, de outro, molda comportamentos que visam à conformação e aceitação da violência, ainda que táticas sejam elaboradas cotidianamente pelos sujeitos.

A Ciência, a Escola, o Processo Penal, a Literatura e a Igreja Católica são instrumentos de divulgação de valores. Pautam a circulação de ideais e representações sociais e foram importantes veículos para apropriação e representação do feminino. A despeito das várias produções normativas e científicas que tratam da autonomia dos gêneros e das mudanças sociais que viabilizam uma maior atuação do feminino na esfera pública, observamos, a partir do fenômeno de santificação popular, que no Cariri cearense a representação do feminino ainda se propaga de modo relacionado aos ideais da família nuclear e o plano da cultura se instrumentaliza em torno dos valores e papéis de gênero consolidados há dois séculos. Essa construção representativa contribui para a manutenção dos papéis e dá vazão à violência de gênero.

\section{Referências}

AREND, Silvia Fávero. Meninas. Trabalho, escola e lazer. In: PINSKY, Carla Bassanezi; PEDRO, Joana Maria (Org.). Nova História das mulheres. São Paulo: Contexto, 2012.

ARAÚJO, Isabelle Maria Mendes de; MORAIS Heloísa Maria Mendonça de. Diálogos entre Mário Magalhães e Josué de Castro: a questão 'saúde e desenvolvimento' nos anos 1950 e 1960. s/Eculum - Revista de História [31]; João Pessoa, jul./dez. 2014.

BANDEIRA, Pedro; BANDEIRA, Daudeth. Quem ama perdoa. Juazeiro do Norte. 1975.

BANDEIRA, Pedro. Deixa meu amor morrer. Juazeiro do Norte. 1975.

BARRETO, Polliana de Luna Nunes. Educação e Santidade: as Representações do Feminino na região do Cariri cearense. Tese (Doutorado em História). Fortaleza: Universidade Federal do Ceará, 2018.

BOURDIEU, Pierre. A dominação masculina: a condição feminina e a violência simbólica. Rio de Janeiro: Edições Best Bolso, 2014.

BRASIL. Processo-crime Nº 0000.046.02959-1. Comarca de Mauriti. Ceará. 1975.

CERTEAU, Michel. A invenção do cotidiano: Artes de fazer. Vol. 1. Petrópolis: Vozes, 1994.

CHARTIER, Roger. A História Cultural: entre práticas e representações. São Paulo: Difel, 1990.

CÓDIGO DE DIREITO CANÔNICO. 10. ed. São Paulo: Loyola, 1997.

FOUCAULT, Michel. História da sexualidade 2: o uso dos prazeres. São Paulo: Graal, 2012.

FOUCAULT, Michel. História da sexualidade 1: a vontade de saber. Rio de Janeiro, Paz e Terra, 2014. 
GOIANA .Ivaneide Severo; QUEIROZ, Zuleide Fernandes de. Educação Na Congregação Das Filhas De Santa Teresa De Jesus: Um Resgate Histórico das Instituições Teresianas na Região do Cariri. In: Congresso de História da Educação da Sbhe, 7. 2013, Cuiabá. Atas.

SAFFIOTI, Heleneith. Gênero, patriarcado e violência. São Paulo: Fundação Perseu Abramo, 2004.

SCHWARTZMAN, Simon. Ciência, Universidade e ideologia: a política do conhecimento. Rio de Janeiro: Zahar, 1981.

SCOTT, Joan W. Gênero: uma categoria útil de análise histórica. Educação e Realidade, vol. 16, n² 2, Porto Alegre, jul./dez. 1990.

SOUZA, Vanderlei Sebastião de. Retratos da nação: os 'tipos antropológicos' do Brasil nos estudos de Edgard Roquette-Pinto, 1910-1920. Bol. Mus. Para. Emílio Goeldi. Cienc. Hum., Belém, v. 7, n. 3, p. 645-669, set.-dez. 2012.

\section{Notas de autoria}

Polliana de Luna Nunes Barreto, Universidade Federal do Cariri (UFCA). Licenciada em História. Doutora em Educação pela Universidade Federal do Ceará (UFC). Professora da Universidade Federal do Cariri. Ministra aulas no Instituto Interdisciplinar de Sociedade Cultura e Artes. Desenvolve pesquisas em Educação, História e Memória, Gênero e Políticas Educacionais. E-mail: polliana.luna@ufca.edu.br.

Patrícia Helena Carvalho Holanda, Universidade Federal do Ceará (UFC). Psicóloga, Doutora em Educação pela Universidade Federal do Ceará (UFC), Pós-doutora pela Universidade de Lisboa. Professora do Programa de Pós-Graduação em Educação da UFC, vinculada à linha de pesquisa História e Educação Comparada, sob sua coordenação. E-mail: profa.patriciaholanda@gmail.com.

\section{Como citar esse artigo de acordo com as normas da revista}

BARRETO, Polliana de Luna Nunes; HOLANDA, Patrícia Helena Carvalho. O feminino sacralizado e a violência de gênero no Cariri: do processo-crime à poesia. Sæculum Revista de História, v. 24, nº 41, p. 248-266, 2019.

\section{Contribuição de autoria}

Elaboração e contribuição coletiva.

\section{Consentimento de uso de imagem}

Não se aplica.

\section{Aprovação de comitê de ética em pesquisa}

Não se aplica.

\section{Licença de uso}

Este artigo está licenciado sob a Licença Creative Commons CC-BY. Com essa licença você pode compartilhar, adaptar, criar para qualquer fim, desde que atribua a autoria da obra.

\section{Histórico}

Artigo recebido em 31/07/2019.

Artigo aprovado em 14/09/2019. 